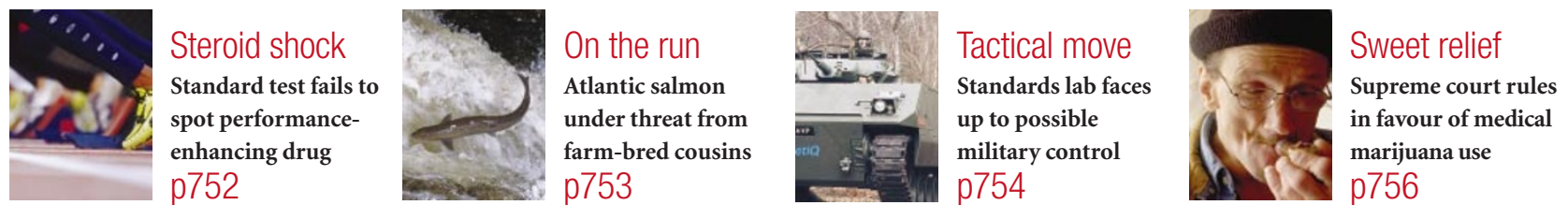

\title{
Biosafety trials darken outlook for transgenic crops in Europe
}

\section{Jim Giles, London}

The results are in from the largest investigation so far into the ecological impact of transgenic crops - and they're bad news for agricultural biotechnology.

Britain's Farm Scale Evaluations, published on 16 October, show that two genetically modified crops - spring oilseed rape and beet - are likely to have harmful impacts on farmland biodiversity. Researchers say the levels of weeds, seeds and insects in fields of transgenic crops were lower than those in plots of conventional varieties, and that this could have a knock-on effect on the birds and small animals that feed off these populations.

Although the problems are caused by the herbicide-spraying regime associated with the crops, rather than the crops themselves, the results are likely to make it politically impossible for the British government to license transgenic crops in the immediate future, many observers say. That's a blow for supporters of the technology in the United States, who had been looking to Britain for potential support in their attempts to persuade Europe to accept the technology.

The trials, which took place between 2000 and 2002 and are published as eight papers in the Philosophical Transactions of the Royal Society $B$, compared conventional and transgenic varieties across 200 plots.

Positive results for a third crop — maize (corn) - have been called into doubt, as the weed-killer used on most of the conventional plants is to be phased out. But the other results have not been directly challenged by most supporters of the technology. The data show that the number of seeds on the ground in the plots of transgenic oilseed rape and beet was one-third to one-sixth lower than in the conventional plots. Levels of some insects and weeds were also lower. "We could see a long-term decline in weeds that feed birds," says Les Firbank, a land-use specialist at Lancaster University, who led the trials.

Firbank and the other authors stress that it is the herbicide-spraying regime, not the genetic modification, that is the root of the problem. Herbicide-resistant crops are engineered to resist broad-spectrum weed-killers that remove almost all weeds from a field.

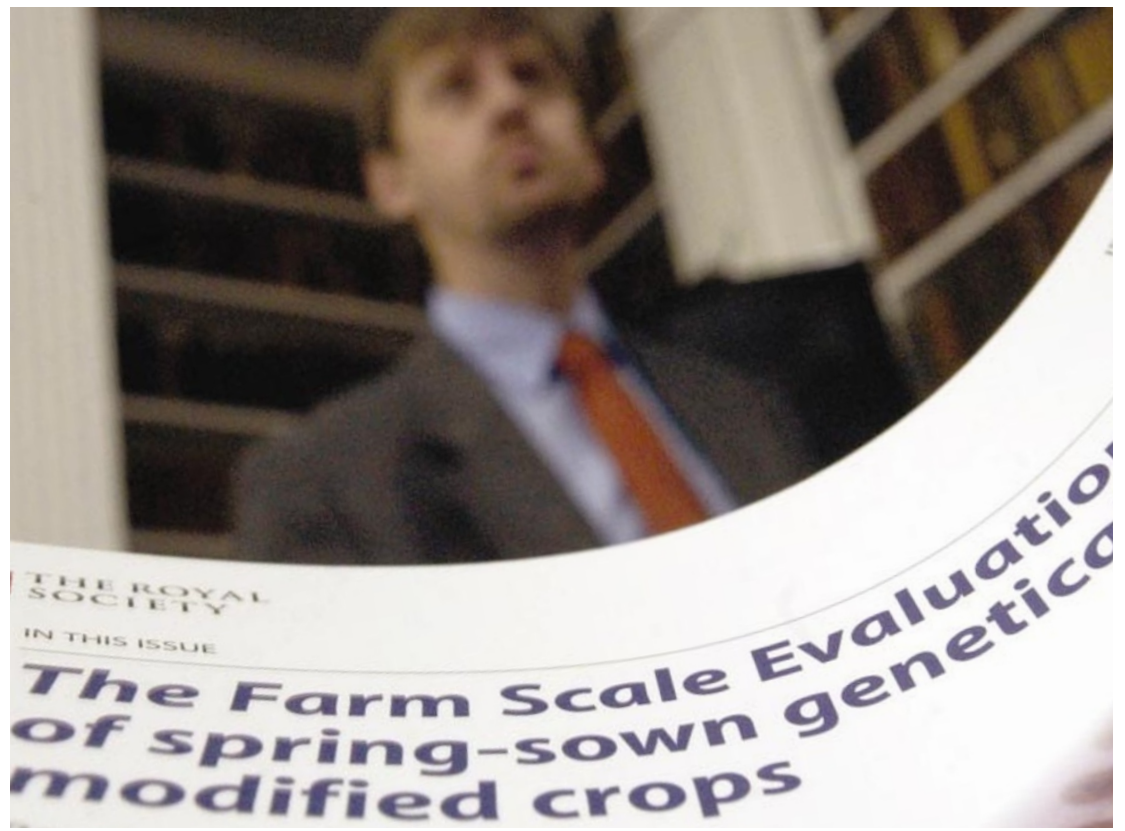

Scaled down: a study finds reduced levels of insects and seeds on which birds and small animals feed.

During the farm-scale evaluations, farmers sprayed the crops once or twice with a broad-spectrum herbicide. This reduces the labour required for conventional weed management, which involves repeatedly applying less powerful weed-killers. But the more powerful herbicide used with the transgenic crops also removes more weeds, as well as the seeds they produce.

Representatives of the agriculture industry point out that this leaves open the possibility that another herbicide-spraying regime might have lessened the impact on biodiversity while still reducing farmers' labour. "This was a test of management systems," says Craig Stevenson, head of government affairs at the London office of the agricultural biotechnology company Monsanto. "These can be changed very easily. We're still confident that transgenic crops can bring benefits."

But given the intense public opposition to transgenic agriculture, the chances of commercializing herbicide-resistant crops in the short term are slim (see Nature 425, 656-657; 2003). Many surveys of public attitudes, including a government-commissioned public debate, have recorded opposition to commercialization, and the field-trial results are likely to strengthen this sentiment.

No decision will be made until a panel of scientific advisers has considered the results for the government. But environment minister Elliot Morley has already said that no commercial planting will take place in 2004.

In the meantime, work on better spraying regimes continues. Alan Dewar, an entomologist at Broom's Barn Research Station in Bury St Edmonds, Suffolk, and a researcher on the farm-scale evaluations, has studied the effect of delaying spraying beet until later in the crop's life, and of retaining herbicidefree strips between rows of crops. The experiments, which are partly funded by Monsanto, found that the effects on biodiversity may be no worse than with conventional crops. "But when I saw the headlines last week I wondered if we would ever get the chance to prove it," he says.

Additional reporting by Michael Hopkin.

www.defra.gov.uk 